Research Article

\title{
Frequency of UTI in Children Presenting with Fever without Focus
}

\author{
Asma Danish ${ }^{*}, 1$ Malahat Sohaib², Uzma Abdul Jabbar², Samina Shamim² \\ ${ }^{1}$ Department of Clinical Hematology, National Institute of Blood Disease \& Bone Marrow Transplantation, Karachi, Pakistan. \\ ${ }^{2}$ Department of Pediatric Medicine, Liaquat National Hospital, Karachi, Pakistan.
}

\begin{abstract}
Objective: To determine the frequency of Urinary tract infections in children presenting with fever without a focus - a tertiary care hospital experience.

Material and Methods: It is a descriptive cross sectional study to find out the frequency of UTI conducted from 26th April to 25th October 2013. Patients of either gender, 1 month to 36 months of age, presenting with the complaints of fever without focus were included. History and physical examination were done; urine sample was collected for analysis and culture. Data was recorded on a pre designed Proforma. Mean and standard deviation for quantitative, frequencies and percentages for qualitative variables were computed. Stratification was done to observe the effects of modifiers on outcome. Post stratification chi square test was applied and $p$ value $\leq 0.05$ was considered as significant.
\end{abstract}

Results: Among total 126 study subjects 62 patients were male. The mean age was $13.96 \pm 8.56$ months. Mean age of patients was $13.88 \pm$ 6.50 months and $13.97 \pm 8.86$ months for patients with and without UTI respectively. Among patients with urinary tract infection, $9(52.9 \%)$ were male and $8(47.1 \%)$ were female patients. Age of $9(52.9 \%)$ patients was $\leq 13$ months and age of $8(47.1 \%)$ patients was $>13$ months. There was no significant association of UTI observed with gender $(p=0.741)$ and age $(p=0.794)$.

Conclusion: UTI is a common infection that can be easily missed in young children. Screening patients at risk can lead to proper diagnosis and a reduction in morbidity.

Keywords: Urinary tract infection, Fever without focus, Urine culture, Urine DR, Morbidity, Bacterial infection.

\section{INTRODUCTION}

Fever without focus is an obscure clinical phenomenon for young children [1] It specifies a child with history of documented fever of at least 1 week duration without any compelling examination findings [2]. In approximately, 20\% of children who present in outpatient clinics with significant history of fever, no focal point is identified after meticulous clinical assessment [3-5].

The causative factor can be either bacterial or viral. The incidence of bacterial infection varies from $3 \%$ to $15 \%$ in these cases [6-8].

In children core body temperature of $>37.7 \mathrm{C}(100.4 \mathrm{~F})$ is considered significant enough for evaluation of any serious occult bacterial infection including UTI [8].

UTI is an infection of any part of urinary tract and occurs when the tract is invaded by bacteria. It is subdivided into two types. 1. Upper urinary tract infection (involving kidney and ureters) 2 lower urinary tract infection involving (urethra and bladder). History and physical examination alone cannot differentiate between these two types. A number of laboratory and radiological investigations are required to confirm either of the two types [9-11].

*Address correspondence to this author at the Department of Clinical Hematology, National Institute of Blood Disease \& Bone Marrow Transplantation, Karachi, Pakistan.. E-mail:asmakarm@hotmail.com
Urinary tract infections (UTIs) are a common cause of morbidity in children [12, 13]. If UTI is missed or inappropriately treated, the long term sequelae might lead to renal scarring and dysfunction [14]. UTI is five times more common in males compared to females from birth till $3^{\text {rd }}$ month which is contrary to the incidence later on in life [15].

Urinary tract infections (UTIs) are almost always occult in febrile children younger than 2 years of age [8]. In Pakistani population, Rehman et al. reported that the frequency of UTI among children is close to $(37.5 \%)$, out of which $36(9.6 \%)$ were male and $339(90.4 \%)$ were females. $48.5 \%$ of his patients were younger than 3 years [2].

The morbidity of the urinary tract infection (UTI) in infancy is very high resulting in renal damage with symptoms ranging from mild hypertension to end stage renal failure $[16,17]$. In childhood, UTI is 2 to 4 fold more prevalent in girls than in boys, and $5 \%$ of school girls have UTI during their school years $[18,19]$. In children, within one to two years of the first diagnosed UTI, renal parenchymal defects are noticed in $3-15 \%$ of children.

Attempts to estimate the prevalence of UTI in children age 2 months to 2 years of age with no apparent source of fever have had varying success. For example, Shaw, Gorelick, McGowan et al. investigated prevalence rates of UTI among females under 2 years old and males under 1 year of age who 
had a fever of equal to or greater than 38.5 degrees Celsius [20] Caucasian females were found to have a $16.1 \%$ prevalence rate of UTI. This finding is similar to the $16.0 \%$ prevalence rate of UTI among Caucasian females whose highest temperature was equal to or greater than $39 \mathrm{C}$. documented by Hoberman et al. [20].

The best and reliable way to diagnose a urinary tract infection is culture but it takes a lot of time for the report to finalize. If the urine $\mathrm{dr}$ report shows a combination of $\geq 10 \mathrm{WBC} / \mathrm{hpf}$ and bacteriuria (on either centrifuged or uncentrifuged urine) [21] along with more readily available urine dipstick (positive for either leukocyte esterase or nitrites) the sensitivity reaches upto $88 \%$ [22]. Treatment should be started immediately upon detection of any positive result.

The aim of this research is to know the incidence of UTI as a cause of fever without focus in our setup. This will not only help in diagnosing UTI but will also help in preventing complications associated with untreated UTI. The data might prove conducive in developing a departmental protocol for performing urine analysis in all children presenting with fever without focus thereby ensuring timely diagnosis, treatment and prevention of future complications associated with UTI.

\section{MATERIALS AND METHODS}

The study was conducted at Pediatric Department of Liaquat National Hospital, Karachi, from 26th April 2013 to 25th October 2013. The sample size of 126 patients was included in this study. It was a descriptive cross sectional study. Non-probability consecutive sampling was used as the method for patients' enrollment in the study. Patients of either sex, having ages between $1-36$ months, presenting with fever of less than week duration without any localizing focus were included. All children who have any localizing focus like rash, respiratory, cardiological, neurological, abdominal, musculoskeletal and urogenital sign and symptoms. Those who have received antimicrobial agent within last 48 hours, or undergone bladder catheterization within 48hours, or any surgical procedure of urinary tract in the past or have any urogenital abnormalities were excluded.

A written informed consent was taken from parents/guardians of each patient. Patient's history and physical examination was conducted by the principle investigator. After thorough clinical evaluation, urine sample was collected for analysis and culture by clean catch method from each child. Urine analysis was done on Urysis 2400. Urine specimen was cultured on CLED agar plate (cysteine lactose, electrolyte deficient).

Data was analyzed using Statistical Package for Social Sciences (version 21). Mean and standard deviation were computed for the quantitative variable i.e. age. Frequencies and percentages were computed for the qualitative variables i.e. gender, fever, circumcision, urine $\mathrm{C} / \mathrm{S}$, urine $\mathrm{DR}$, and UTI. Effect modifiers like age and gender were controlled by stratification to observe the effects of these modifiers on outcome. Post stratification chi square test was applied and $\mathrm{p}$ value $\leq 0.05$ was taken as significant.

\section{RESULTS}

126 children of either gender ranging from age 1 month to 36 months and had complaint of fever for less than one week duration without any localized focus of infection were evaluated to determine the frequency of Urinary tract infections (UTI).

Among total study subjects, $62(49.2 \%)$ children were male and $64(50.8 \%)$ patients were female. Among male patients, $57(91.9 \%)$ patients had circumcision done and not yet done in only $5(8.1 \%)$ patients. The mean age was $13.96 \pm 8.56$ months, $63(50 \%)$ patients age $\leq 13$ months, the mean age of these patients was $6.95 \pm 3.46$ months. Rests of the $63(50 \%)$ patients aged $>13$ months, the mean age of patients in this group was $20.97 \pm 5.99$ months.

Among overall 126 patients, the urine culture sensitivity was found organism isolated in $17(14 \%)$ patients. 10 patients out of 17 had significant growth of E coli (105 organisms/ HPF) Urinalysis reports showed presence of pus cells in 13 patients and not found in 113 patients.

Positive urinary tract infection showed that age of 9 patients was $\leq 13$ months and age of 8 patients was $>13$ months. However, there was no significant association of UTI with age (in months) (Table 1) ( $\mathrm{p}=0.794)$.

Among total 17 patients with positive urinary tract infection, 9 were male and 8 were female patients. The results showed that no significant association of UTI was observed with gender (Table 1) $(\mathrm{p}=0.741)$.

Table 1. Frequency and Association of Urinary Tract Infection with Age And Gender.

\begin{tabular}{|c|c|c|c|c|}
\hline & \multicolumn{3}{|c|}{ URINARY TRACT INFECTION } & \multirow[b]{2}{*}{ P-value } \\
\hline & $\begin{array}{l}\text { Positive }(n=17) \\
\text { Frequency (\%) }\end{array}$ & $\begin{array}{l}\text { Negative }(n=109) \\
\text { Frequency }(\%)\end{array}$ & TOTAL & \\
\hline$\leq 13$ months & $9(14.3)$ & $54(85.7)$ & 63 & 0.794 \\
\hline$>13$ months & $8(12.7)$ & 55(87.3) & 63 & \\
\hline Total & 17(13.5) & $109(86.5)$ & 126 & - \\
\hline Male & $9(14.5)$ & $53(85.5)$ & 62 & 0.741 \\
\hline Female & $8(12.5)$ & $56(87.5)$ & 64 & \\
\hline Total & 17(13.5) & $109(86.5)$ & 126 & - \\
\hline
\end{tabular}




\section{DISCUSSION}

Majority studies have quoted a positive Urine culture $(>100,000 \mathrm{CFU} / \mathrm{ml})$ as being diagnostic of UTI in addition to pyuria (more than 5 white cells per high powered field on microscopy) and bacteriuria. Presence of both pyuria and bacteriuria from a fresh urine sample is highly indicative for possible UTI although not diagnostic [23].

Numerous studies have attempted to determine the prevalence of UTI in infants and young children. A comprehensive review of the literature was submitted by the Urinary Tract Subcommittee of the AAP in 1999. The Committee concluded $5 \%$ prevalence in children age group 2 months to 2 years of age [24].

Girls are more prone to develop urinary tract infection owing to a shorter urinary tract. Thus all females from age 3 to 24 months with a significantly higher core body temperature and no other specific symptoms should have their urine analysis and culture done. Some researchers have also urged the need to do urine studies for highly febrile boys between 3 to 24 months of age [11]. In our study, the no such difference of age 9 patients age less than or equal to 13 months and 8 patients aged more than 13 months.

Pakistan is a developing nation with majority of population at risk of serious occult infections, urinary tract infection being one of them. A study from Yemen cotes 375 out of 1000 (37.5\%) febrile patients were diagnosed as having UTI [25], the percentage of which is quite low in comparison to other studies [1]. Our study showed no significant difference with respect to gender which is different from some other studies showing 1:10 male to female ratio [26]. In yemen study male to female ratio was $1: 26$ [25] which might be due to early circumcision practices in that country. In our study children less than 3 years constitute less than half of the total infected cases similar to other studies [27]. This might be due to toilet training issues at this early age [28].

Studies show an association of UTI with fever in $91 \%$ cases [29]. Color, smell or turbidity of urine had no relationship with UTI. Around $88 \%$ of cases of UTI had no change in color or smell of urine [29]. Recurrent episodes of UTI were associated with poor compliance to initial treatment for UTI, infrequent follow-up visits and anatomic abnormalities of urinary tract. In our study associated other symptoms were urethral discharge and palpable urinary bladder comparable to other studies with similar incidence [30].

In this study, after screening 126 children, the overall prevalence of UTI (boys and girls) was calculated to be $13.5 \%$, whereas the prevalence of UTI in boys was $14.5 \%$ and in girls it was calculated to be $12.5 \%$. In Jordan, a study was conducted to determine conditions that result in pediatric nephrology consultations in the academic hospital of Jordan University in the age group from one day to 16 years and found that urinary tract infections account $14.2 \%$ of consultations [31].

\section{CONCLUSION}

As UTI in children often goes undetected owing to infrequent symptomatology a coherent clinical approach is required in which all febrile children with no other focus of infection be screened for the presence of this occult infection. It will lower the incidence and will prevent children from developing long term renal damage.

\section{LIMITATIONS OF STUDY}

- Unicenteric study.

- Limited sample size.

\section{CONFLICT OF INTEREST}

Declared none.

\section{ACKNOWLEDGEMENTS}

Declared none.

\section{REFERENCES}

[1] Bleeker SE, Moons KGM, Derksen-Lubsen G, Grobbee DE, Moll HA. Predicting serious bacterial infection in young children with fever without apparent source. Acta Paediatr 2001; 90: 1226-32.

DOI: $10.1111 / \mathrm{j} .1651-2227.2001 . t b 01566 . x$

[2] Powell KR. Fever without a focus. In: Behrman RE, Kleigman RM, Arvin AM, Eds. Nelson Textbook of Pediatrics. Philadelphia (PA): Saunders 1996; pp. 698-704.

[3] Lee GM, Harper MB. Risk of bacteremia for febrile young children in the post-Haemophilus influenzae type B era. Arch Pediatr Adolesc Med 1998; 152: 624-8.

DOI: 10.1001/archpedi.152.7.624

[4] Baraff LJ, Lee SI. Management of fever without source in infants and children. Ann Emerg Med 2000; 36(6): 602-14. DOI: $10.1067 / \mathrm{mem} .2000 .110820$

[5] Soman M. Characteristics and management of febrile young children seen in a university family practice. J Fam Pract 1985; 21: 117-22.

[6] Kuppermann N, Fleisher GR, Jaffe DM. Predictors of occult pneumococcal bacteremia in young febrile children. Ann Emerg Med 1998; 31: 679-87.

DOI: $10.1016 / \mathrm{S} 0196-0644(98) 70225-2$

[7] Greenes DS, Harper MB. Low risk of bacteremia in febrile children with recognizable viral syndromes. Pediatr Infect Dis J 1999; 18: 258-61.

DOI: 10.1097/00006454-199903000-00010

[8] Baraff LJ, Oslund SA, Schriger DL, Stephen ML. Probability 
of bacterial infections in febrile infants less than three months of age: a meta-analysis. Pediatr Infect Dis J 1992; 11: 257-64. DOI: 10.1097/00006454-199204000-00001

[9] Hickey RW, Bowman MJ, Smith GA. Utility of blood cultures in pediatric patients found to have pneumonia in the emergency department. Ann Emerg Med 1996; 27: 721-5.

DOI: 10.1016/S0196-0644(96)70189-0

[10] Majd M, Rushton HG. Renal cortical scintigraphy in the diagnosis of acute pyelonephritis. Semin Nucl Med 1992; 22: 98-111. DOI: 10.1016/S0001-2998(05)80085-6

[11] Hoberman A, Wald ER. Urinary tract infections in young febrile children. Pediatr Infect Dis J 1997; 16: 11-7. DOI: 10.1097/00006454-199701000-00004

[12] Anis-ur-Rehman, Jahanzeb M, Siddiqui TS, Idris M. Frequency and clinical presentation of UTI among children of Hazara Division, Pakistan. J Ayub Med Coll Abbottabad 2008; 20(1): 63-5.

[13] Paterson A. Urinary tract infection: An update on imaging strategies Eur Radiol 2004; 4: 89-100.

DOI: $10.1007 / \mathrm{s} 00330-003-2038-\mathrm{x}$

[14] Adjei O, Opoku C. Urinary tract infections in African infants. Int J Antimicrob Agents 2004; 24(1): 32-4.

DOI: 10.1016/j.ijantimicag.2004.02.007

[15] Langely JM. Hanakowski M, Leblanc JC. Unique epidemiology of nosocomial urinary tract infection in children. Am J Infect Control 2001; 29: 94-8.

DOI: $10.1067 /$ mic. 2001.111537

[16] Elder JS. Urinary tract infection. In: Kliegman RM, Behrman RE, Jenson HB, Stanton BF, Eds. Nelson Textbook of Pediatrics. $18^{\text {th }}$ ed. Philadelphia, USA: Saunders 2007.

[17] Wald ER. Cystitis and pyelonephritis. In: Feigin RD, Cherry JD, Demmler GJ, Kaplan SHL, Eds. Text book of pediatric infectious diseases. $5^{\text {th }}$ ed. Philadelphia, USA: Saunders 2004.

[18] Gervaix A, Galetto-Lacour A, Gueron T, et al. Usefulness of procalcitionin and CReactive rapid tests for the management of children with urinary tract infection. Pediatr Inf Dis J 2001; 20(5): 507-11 DOI: 10.1097/00006454-200105000-00007

[19] Kaushal RK, Bansal S, Sharma VK, Sood A, Goyal A. Urinary tract infection among children presenting with fever. Indian Pediatr 2003; 40(3): 269-70.
[20] Al-Orifi F, McGillivray D, Tange S, Kramer MS. Urine culture from bag specimens in young children: are the risks too high? J Pediatr 2000; 137: 221-6.

DOI: $10.1067 / \mathrm{mpd} .2000 .107466$

[21] Huicho L, Campos-Sanchez M, Alamo C. Meta-analysis of urine screening tests for determining the risk of urinary tract infection in children. Pediatr Infect Dis J 2002; 21(1): 1-11. DOI: $10.1097 / 00006454-200201000-00002$

[22] Gorelick MH, Shaw KN. Screening tests for urinary tract infection in children: A meta-analysis. Pediatrics 1999; 104(5): 54. DOI: $10.1542 /$ peds.104.5.e54

[23] Practice parameter: The diagnosis, treatment, and evaluation of the initial urinary tract infection in febrile infants and young children. American Academy of Pediatrics. Committee on quality improvement. Subcommittee on urinary tract infection. Pediatric 1999; 103(4): 843-52. DOI: 10.1542/peds.103.4.843

[24] Mohanna, MA, Raja' a YA. Frequency and treatment of urinary tract infection in children subjected to urine culture, in Sana'a Yemen. J Ayub Med Coll 2005; 17(2): 20-2.

[25] Larcombe J. Urinary tract infection in children. Bio Med J 1999; 319: 1173-5. DOI: 10.1136/bmj.319.7218.1173

[26] Hutchison JH, Cockburn F. Practical Pediatric Problems. $6^{\text {th }}$ ed. London: Lliyd-luke (medical books) 1986.

[27] Mehr SS, Powell CV, Curtis N. Cephalosporin resistant urinary tract infections in young children. J Paediatr Child Health 2004; 40(2): 48-52.

DOI: $10.1111 /$ j.1440-1754.2004.00290.x

[28] Qureshi MA. Clinical presentation of urinary tract infection among children at Ayub Teaching Hospital Abbottabad. J Ayub Med Coll 2005; 17(2): 79-81.

[29] Saleh SI, Tuhmaz MM, Sarkhouh MY. Urinary tract infection in children in Al-jahra area, Kuwait: An overview. Kuwait Med J 2003; 35(1): 31-5.

[30] Al-Momani T. Microbiological study of urinary tract infection in children at Princess Haya Hospital in South Jordan. Middle East J Fam Med 2006; 14(2): 15-8.

[31] Shaikh N, Morone NE, Bost JE, Farrell MH. Prevalence of urinary tract infection in childhood: A meta-analysis. Pediatr Infect Dis J 2008; 27(4): 302-8.

DOI: $10.1097 / \mathrm{INF} .0 \mathrm{~b} 013 \mathrm{e} 31815 \mathrm{e} 4122$ 